\title{
Amelanotic Melanoma Presenting as a Neuropathic Ulcer in a Non-Diabetic Patient
}

\author{
David Mark ${ }^{\mathrm{a}, \mathrm{c}}$, Susan Yoong ${ }^{\mathrm{a}}$, Julie Reid ${ }^{\mathrm{a}}$, Khalid Khan ${ }^{\mathrm{b}}$
}

\begin{abstract}
Amelanotic melanoma can often confound clinicians due to its variable presentation and non pigmented characteristics that can mimic neuropathic ulceration. We report here an 85 year old non-diabetic gentleman who presented to the vascular service with a six month history of non healing neuropathic ulcer overlying his 5th metatarsal head. Further investigations revealed an amelanotic malignant melanoma.
\end{abstract}

Keywords: Amelanotic; Acral lentiginous; Melanoma, Neuropathic ulcer; Non-diabetic; Plantar; Surgery

\section{Introduction}

Amelanotic malignant melanoma is a rare form of skin cancer which is commonly misdiagnosed due to its variable presentation and clinical appearance [1-3]. This can often lead to a worse prognosis due to delay in management and treatment [4-6]. We describe a case of amelanotic malignant melanoma mimicking a neuropathic ulcer in a non-diabetic patient.

\section{Case Report}

This 85 year old non diabetic patient presented to our vascular clinic with a six month history of a painless, hypergranulated $5 \mathrm{~cm}$ ulcer on the planter aspect of his left foot overlying the 5th metatarsal head (Fig. 1). Initial community based management with antibiotics and regular dressings showed no improvement to the ulceration. Further investigations from clinic showed no evidence of infection or underlying osteomyelitis raising the clinical suspicion of an amelanotic melanoma. Punch biopsy of the lesion revealed malignant melanoma with Computerised Tomography (CT) staging

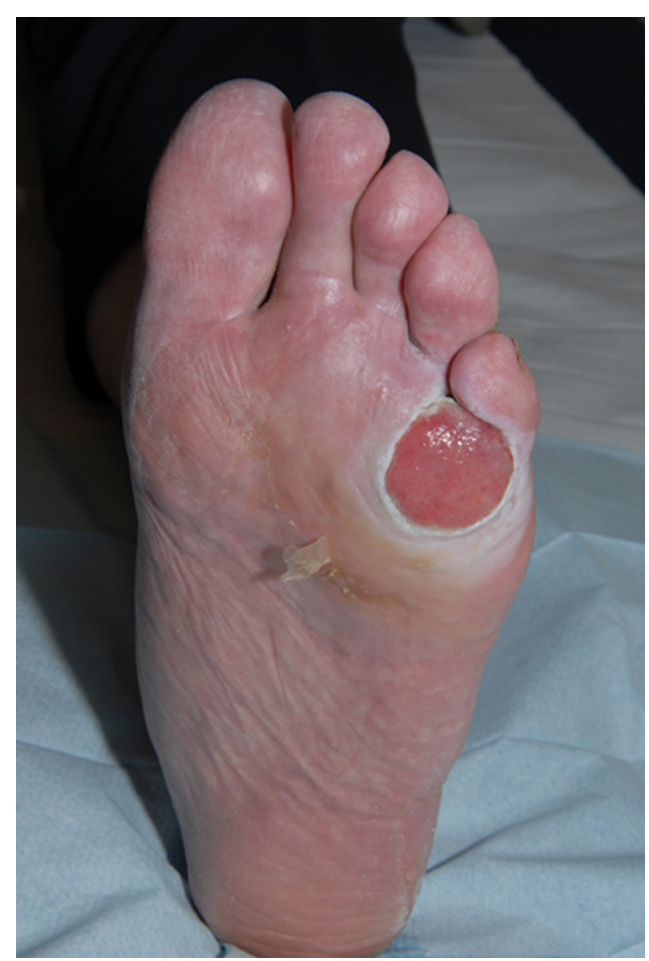

Figure 1. Amelanotic melanoma mimicking neuropathic ulcer. 


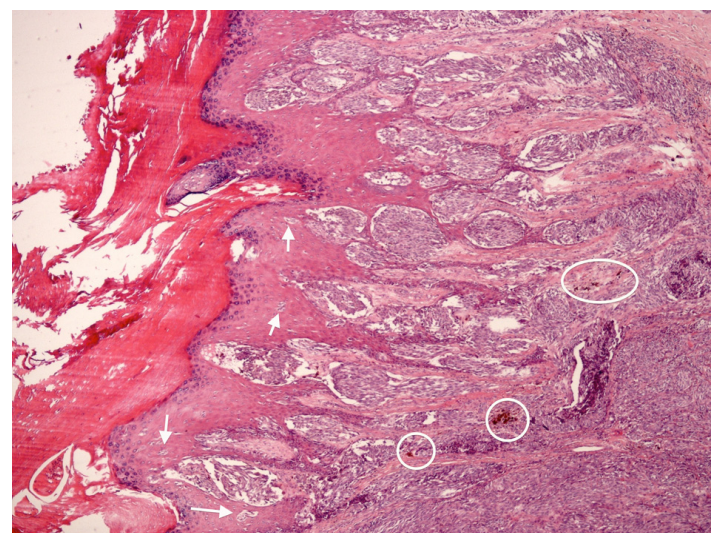

Figure 2. Original magnification $\times 100$. Histology showing pigmented deposition (circled) a characteristic feature of melanoma and upward migration of melanocytes through the epidermis (arrowed) a feature of malignancy.

showing no evidence of distal metastases. The patient was referred to the Plastic Surgeons who excised the lesion, which involved an amputation of his fifth toe at the level of the metatarsal joint and reconstruction with a split skin graft. The pathology report confirmed the presence of acrallentiginous melanoma of $17 \mathrm{~mm}$ Breslow depth. The lateral margin of clearance was $12 \mathrm{~mm}$ and the deep $2.5 \mathrm{~mm}$ (Fig. 2, $3)$. After further discussion at a multidisciplinary team meeting no further resection was needed or adjuvant treatment required. Less than one year later the patient was re-referred to the oncology service with local disease recurrence with nodular lesions to his left foot, lower limb and groin. Further imaging with CT and Positron Emission Tomography (PET) scanning confirmed left foot, leg and nodal metastasis to groin. A six week course of palliative radiotherapy was commenced with good symptomatic improvement. Review three months later showed rapidly progressive local recurrence with further radiotherapy having only a limited impact.

\section{Discussion}

The incidence of malignant melanoma has increased dramatically over recent years with Acral lentiginous melanoma accounting for less than $10 \%$ of primary cutaneous melanomas diagnosed. Despite its relative rarity this form of melanoma represents an aggressive lesion with a predilection for the plantar surface of the feet, palms of the hand and digits [79]. Melanoma presenting on plantar and subungal sites are associated with a higher rate of misdiagnosis and subsequent delay to management and intervention, relative to other anatomical sites [10]. The propensity for plantar surfaces along with the amelanotic nature of our patients melanoma were important factors in delaying his referral to a tertiary center. Delayed diagnosis of amelanotic melanoma in the diabetic patient has been well documented but this is the first such

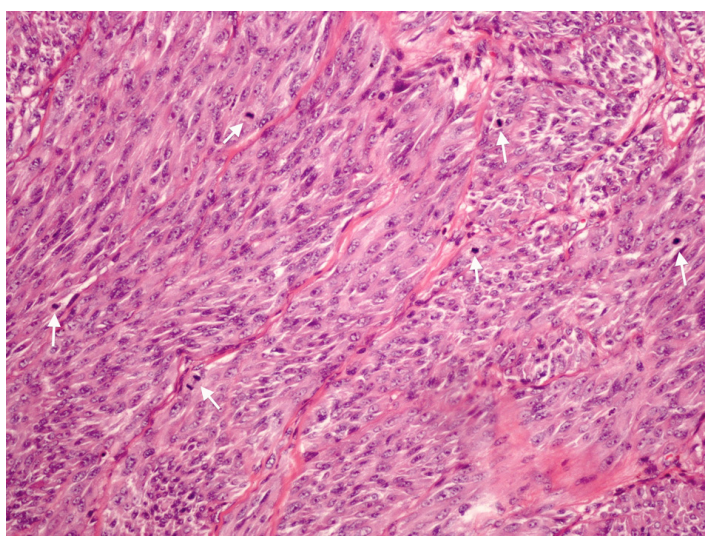

Figure 3. Original magnification $\times 200$. Cytological features of epithelioid to spindled cells with prominent nucleoli. Arrows highlighting brisk mitotic activity.

case describing a non diabetic patient with a lesion masquerading as neuropathic ulcer $[1-3,10]$. This case highlights the importance of a raised index of clinical suspicion when presented with a non progressing foot ulcer despite appropriate medical management. Despite a normal CT scan at initial diagnosis the case discussed went on to have rapidly progressive disease with metastatic involvement further illustrating the importance for greater awareness and need for an aggressive management strategy in such cases.

\section{Conflict of Interest}

All authors declare that they have no conflict of interest.

\section{References}

1. Torres T, Rosmaninho A, Caetano M, Selores M. Malignant melanoma misdiagnosed as a diabetic foot ulcer. Diabet Med. 2010;27(11):1302-1303.

2. Rogers LC, Armstrong DG, Boulton AJ, Freemont AJ, Malik RA. Malignant melanoma misdiagnosed as a diabetic foot ulcer. Diabetes Care. 2007;30(2):444-445.

3. Gregson CL, Allain TJ. Amelanotic malignant melanoma disguised as a diabetic foot ulcer. Diabet Med. 2004;21(8):924-927.

4. Balch CM, Murad TM, Soong SJ, Ingalls AL, Halpern NB, Maddox WA. A multifactorial analysis of melanoma: prognostic histopathological features comparing Clark's and Breslow's staging methods. Ann Surg. 1978;188(6):732-742.

5. Lemont H, Brady J. Amelanotic melanoma masquerading as an ingrown toenail. J Am Podiatr Med Assoc. 2002;92(5):306-307.

6. Fortin PT, Freiberg AA, Rees R, Sondak VK, Johnson TM. Malignant melanoma of the foot and ankle. J Bone 
Joint Surg Am. 1995;77(9):1396-1403.

7. Harmelin ES, Holcombe RN, Goggin JP, Carbonell J, Wellens T. Acral lentiginous melanoma. J Foot Ankle Surg. 1998;37(6):540-545.

8. Rigel DS. Malignant melanoma: incidence issues and their effect on diagnosis and treatment in the 1990s. Mayo Clin Proc. 1997;72(4):367-371.
9. Sutherland CM, Mather FJ, Muchmore JH, Carter RD, Reed RJ, Krementz ET. Acral lentiginous melanoma. Am J Surg. 1993;166(1):64-67.

10. Soon SL, Solomon AR, Jr., Papadopoulos D, Murray DR, McAlpine B, Washington CV. Acral lentiginous melanoma mimicking benign disease: the Emory experience. J Am Acad Dermatol. 2003;48(2):183-188. 